\title{
O Circo como profissão: a formação em Educação Física como suporte para a carreira artística de Gustavo Arruda de Carvalho
}

\author{
Circus as a profession: Physical Education training as a support for Gustavo Arruda de Carvalho's \\ artistic career
}

El circo como profesión: la formación en Educación Física como soporte para la carrera artística de Gustavo Arruda de Carvalho

Marco Antonio Coelho Bortoleto I, Mônica Lua Alves Barreto II

\begin{abstract}
Resumo
O domínio do corpo e o olhar sobre seus múltiplos usos, incluindo o artístico, são amplamente estudados no campo da Educação Física. Diferentes registros indicam haver um movimento crescente entre profissionais da área por aprender e ensinar diferentes linguagens artísticas, como o Circo. Identificamos, ainda, muitos professores de Educação Física que se profissionalizaram como artistas, beneficiando-se de seu capital corporal e acadêmico em busca da realização profissional. Nesse sentido, apresentamos uma entrevista-reflexão realizada com Gustavo Arruda de Carvalho, formado pela Faculdade de Educação Física da Universidade Estadual de Campinas (FEF-Unicamp) e respeitado artista circense profissional.
\end{abstract}

Palavras-chave: Circo; Formação Profissional; Arte; Esporte

\begin{abstract}
The mastery of the body and the look at its multiple uses, including the artistic, has been widely studied in the field of Physical Education. Different records indicate that there is a growing movement among practitioners to learn and teach different artistic languages, including Circus. We also identify those who decided to professionalize themselves as artists, benefiting from their body and academic capital in pursuit of professional fulfillment. In this sense, we present a commented-interview conducted with Gustavo Arruda de Carvalho, who graduated at Physical Education Faculty - University of Campinas (Unicamp) and who is a prominent professional circus artist.
\end{abstract}

Keywords: Circus; Professional Education; Art; Sport

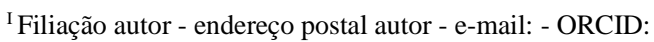

II Filiação autor - e-mail: - ORCID:
} 


\section{Resumen}

El dominio del cuerpo y la mirada a sus múltiples usos, incluido el artístico, ha sido ampliamente estudiado en el campo de la Educación Física. Diferentes registros indican que existe un movimiento creciente entre los profesionales del campo por aprender y enseñar diferentes lenguajes artísticos, como el Circo. Hemos identificado además a muchos profesores de Educación Física que se han profesionalizado como artistas, beneficiándose de su capital corporal y capital académico en busca de la realización profesional. En este sentido, presentamos una entrevistareflexión realizada con Gustavo Arruda de Carvalho, quien se graduó en la Facultad de Educación Física de la Universidad Estatal de Campinas (FEF-Unicamp) y se convirtió en un respetado artista profesional de circo.

Palabras clave: Circo; Educación Profesional; Arte; Deporte

\section{Apresentação}

Diversos estudos mostram que as relações entre o Circo e a Educação Física - nessa ordem, por uma razão histórica - são seculares e ajudaram a constituir as bases da Educação Física como área do conhecimento. Nessa dinâmica, o ir e vir de profissionais, a troca de saberes e outros inúmeros processos alimentam, progressivamente, a literatura especializada (SOARES, 2001; BORTOLETO, 2011; GÓIS JÚNIOR, HAUFFE, 2014; MELO, PERES, 2014; LOPES, EHRENBERG 2020; RIBEIRO, 2015).

Essas relações se tornaram uma destacada particularidade da Faculdade de Educação Física da Universidade Estadual de Campinas (FEF-Unicamp), construindo um amplo conjunto de ações formativas, de pesquisa e de extensão, no campo do Circo, nas últimas duas décadas (BORTOLETO, DUPRAT, TUCUNDUVA, 2016). Nesse contexto, atualmente, há inúmeras formas de interação que relacionam a formação inicial em Educação Física com o Circo, e é por isso que, na universidade, tem sido mais comum a discussão dessas possibilidades de atuação profissional (preparador físico de artistas, professor-pedagogo das atividades circenses, por exemplo), além disso desperta-se o interesse de muitos egressos sem se tornarem artistas profissionais.

De fato, o diálogo que propomos nesta entrevista-reflexão com um egresso da FEF-Unicamp, que se tornou artista circense profissional, não retrata uma exceção, mas uma opção cada vez mais presente na realidade brasileira (BORTOLETO, 2015; BORTOLETO, MIRANDA, 2018; ONTAÑ́́N, BORTOLETO, 2012). Com efeito, o "capital corporal" de ex-atletas, como veremos mais adiante, parece ser um importante elo com a Arte - mais precisamente, com o Circo (RIBEIRO, BORTOLETO, RIGO, 2020). 
O tipo de abordagem acadêmica aqui apresentado, na forma de entrevista-reflexão, parece contribuir para a "autoanálise da Educação Física, propriamente sobre seu campo de ação-formação e sua relação com a Arte. Conhecer a trajetória pessoal, no sentido da construção da carreira profissional no Circo, torna-se, então, uma possibilidade de diálogo com a realidade extrauniversidade e, também, pós-acadêmica. Nesse sentido, cabe recordar que, há mais de 15 anos, publicamos um artigo (BORTOLETO, MACHADO, 2003) ${ }^{1}$, muito provavelmente, o primeiro texto na literatura nacional a abordar o ensino do Circo na Educação Física. Posteriormente, dezenas de outros artigos mostraram que aquela aposta não se tratava de uma elucubração isolada, uma defesa vazia de dois entusiastas da Arte do Circo com raízes acadêmicas na Educação Física, como podemos ver nas análises realizadas por Ontañón, Duprat, Bortoleto (2012). Novamente, a aproximação entre a Educação Física e o Circo, nessa outra ordem, por uma questão do lugar de diálogo, tem acontecido em muitos territórios, no Brasil e no estrangeiro, como exemplifica outra entrevista que realizamos com o Prof. Dr. Kiko León, da Universidade de Extremadura, na Espanha (ONTAÑ́́N, BORTOLETO, 2012).

Com base nesses pressupostos, a seguir, apresentamos uma entrevista-reflexão com Gustavo Arruda de Carvalho, cuja formação inicial em Educação Física foi realizada na FEF-Unicamp². Após uma longa trajetória esportiva, sua atuação profissional foi conduzida para o campo das artes cênicas, convertendo-se num artista circense, ofício que o levou para inúmeros palcos/ picadeiros no Brasil e no mundo nas últimas décadas.

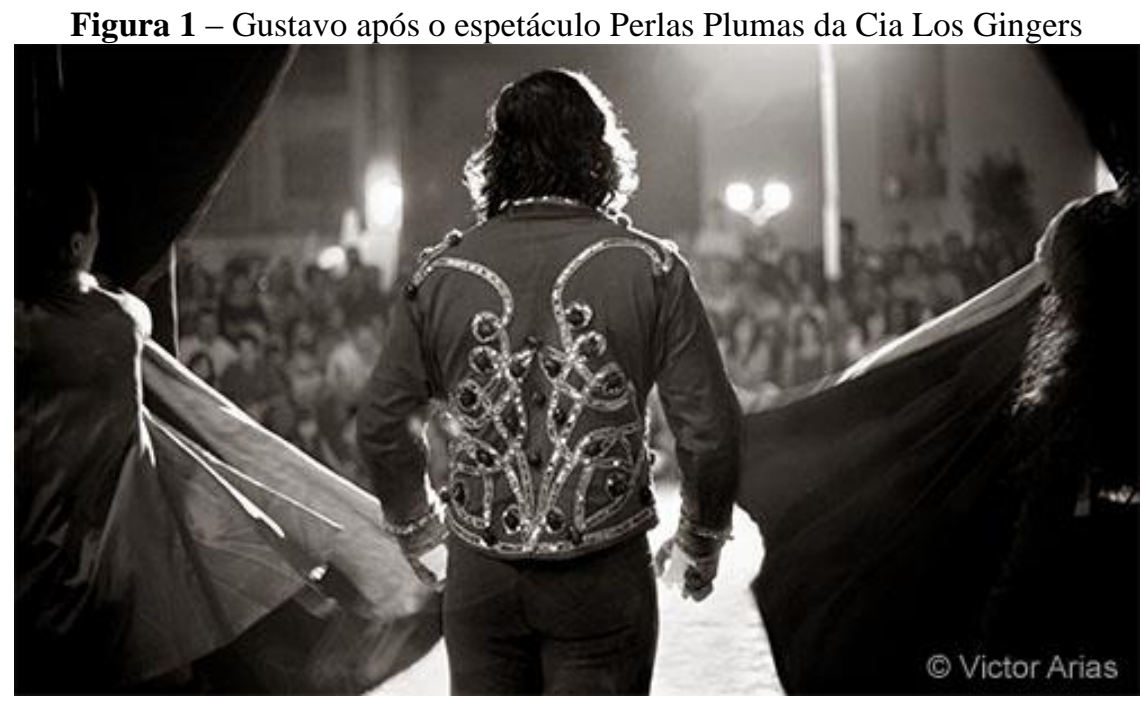

Fonte: Victor Arias León

\footnotetext{
${ }^{1}$ Essa é uma oportunidade para corrigir um erro: o nome correto do autor é Gustavo de Arruda Carvalho (e não "Machado" como publicado na ocasião).

${ }^{2}$ Cabe ressaltar que diversos estudantes da FEF-UNICAMP optaram pelo circo como profissão, caso de a Heber Teixeira Pinto, Rodrigo Mallet Duprat, Marcelo Cazarim Macedo e Lívia de Paula Machado Pasqua, que participaram de diversas temporadas com o Marcos Frota Circo Show; de Andréi Parmezan, com a Cia Acróbatus e Cia Universo Casuo, dentre vários outros, como melhor relatam Bortoleto, Duprat, Tucunduva (2016).
} 


\section{Entrevista}

\subsection{Gustavo, por favor, conte-nos como tudo começou.}

Comecei a fazer ginástica quando ainda era chamada de Ginástica Olímpica, em 1980. De fato, sempre pratiquei muitos esportes, mas a ginástica foi o que levei mais a sério. Treinei no Esporte Clube Pinheiros, em São Paulo, na época coordenado pelo Professor Nestor Soares Publio, deixando os treinamentos por volta de 1986. Retomei o esporte quando entrei na FEF-Unicamp, em 1991, dando aulas no Clube Semanal de Cultura Artística, treinando no Grupo Ginástico Unicamp (GGU), nos horários que conseguia. Também tive a ajuda de um grande amigo e mentor, o Professor Carlos Henrique Silvestre $(\mathrm{Ike})^{3}$, com quem tive a sorte de compartilhar muitas horas de ginástica. Falávamos muito sobre treinamento, biomecânica, neurolinguística e a aplicação prática desses conhecimentos no esporte, no treinamento corporal. Voltei para a competição com a equipe de Campinas, participando de várias edições dos jogos regionais e abertos e de alguns campeonatos universitários. Em 1993, fiz mestrado em Treinamento, em Moscou (Rússia), e tive a oportunidade de treinar um pouco de ginástica no país, a maior potência no esporte naquele momento. Depois, conheci o treinador cubano Emilio Suares, responsável pela seleção de ginástica de seu país, bem como Lázaro Lamelas, seu atleta internacional na ocasião. Compartilhamos treinamentos e muitos saberes durante um mês. Tive ainda a oportunidade de dar aulas de ginástica e contribuir para a formação de alguns ginastas. Enfim, oportunidades incríveis! E o mais importante: sempre tentei aplicar tudo o que aprendia com minhas alunas e alunos, mesmo aquilo que parecia ser radical, estranho, eu experimentava primeiro comigo e, depois, aplicava. Sempre tentei fazer uma ponte entre o conhecimento teórico e a minha experiência prática.

\subsection{Então, foi o professor de Educação Física que encontrou o Circo? Ou o contrário?}

Como comentei, cursei a graduação na FEF-UNICAMP na turma de 1991, finalizando o curso em 1994. Paralelamente, fui treinador de ginástica, ginasta do GGU e um estudioso determinado. Sempre estudei muito, buscando a relação entre a teoria e a aplicação prática. Durante a graduação, o Ike queria montar uma pequena companhia de circo, baseada no tempo que viveu na Europa. Ele falava muito dessa expressão artística, mais precisamente do circo de rua e dos muitos festivais vistos no "velho continente". E, assim, montamos uma pequena "trupe", da qual faziam parte Ike, Conrado, Odilon e eu: "The

\footnotetext{
${ }^{3}$ Foi várias vezes campeão brasileiro de Ginástica Artística, estudou e competiu nos EUA (nível universitário) e representou o Brasil em diversas competições internacionais. Tem dois mestrados em treinamento, um nos EUA e outro na Alemanha.
} 
Borocochos"4. Fizemos muitas atuações em festas infantis, algumas inaugurações, enfim, um período em que sonhávamos pequeno e nos divertíamos muito. Em 1995, a companhia Nau de Ícaros (EVRARD, 2017) convidou-me para ministrar uma formação para seus acrobatas em São Paulo. Trabalhamos juntos até 1996. Nesse momento, começamos a esboçar um projeto de uma escola de circo para adultos e crianças, que deu origem ao projeto do Galpão de Circo, com Alex Marinho. No começo de 1998, apareceu um malabarista espanhol, Tito Medina, que tinha vindo fazer uma reciclagem artística na Escola Nacional de Circo do Rio. Ele veio para São Paulo procurando uma forma mais moderna de aprender acrobacia. Na Europa, nessa época, já existiam professores de acrobacia com formação em Educação Física. Foi uma troca muito grande: ele ensinava malabares e eu, acrobacia. Para mim, foi muito importante ver as infinitas possibilidades que havia no Circo. Fui para a Europa com Tito, à procura de mais conhecimento de Circo. Depois de visitar alguns dos grandes festivais de artes de rua da Europa, fomos para a Escola Nacional de Chatelerault (França), com Joel Suty ${ }^{5}$ estudar trapézio e cama elástica. Em 1999, comecei a trabalhar, como artista de circo, com a companhia Los Galindos e, como professor, no projeto piloto da escola Rogelio Rivell. Tive a oportunidade de me apresentar no amplo circuito de festivais de arte de rua pela Europa, bem como em diferentes países na América e na África. Com o tempo, também passei a trabalhar com teatro de variedades, circos de lona e a realizar projetos de espetáculos pelo mundo. Viajei muito, conheci muitíssimos países e aprendi muitas coisas. Conheci mais e melhor o Circo. Paralelamente, incorporei-me à organização Palhaços Sem Fronteiras (PSF) ${ }^{6}$, realizando diversas expedições mundo afora, que, além de me permitirem conhecer outras realidades - muitas vezes, após catástrofes naturais, guerras, por exemplo, mostraram a arte como um caminho para esse tipo de reconstrução social (BORTOLETO, 2007).

\subsection{Poderia contar algo sobre sua experiência como artista circense?}

Iniciei minha atuação como artista de circo como acrobata e trapezista. Mais tarde, especializei-me em cascatas acrobáticas ${ }^{7}$ e báscula ${ }^{8}$. Tive, no meu caminho, a oportunidade de conhecer e trabalhar com

\footnotetext{
${ }^{4}$ Conrado Federicci é, atualmente, professor doutor na Universidade Federal de São Paulo (Unifesp), palhaço e músico. Odilon José Roble, professor da FEF-Unicamp, estudioso da filosofia do esporte e da dança. Como se vê, há muitas outras tramas que revelam as capilaridades das relações analisadas nesse texto.

${ }^{5}$ Ginasta francês que competiu nos Jogos Olímpicos de 1976, 1980 e 1984.

${ }^{6}$ Dentre os países onde o Palhaços Sem Fronteiras realizou expedições, podemos destacar: México, Guatemala, Croácia, Afeganistão e Croácia.

7 Cascata "designa diferentes tipos de quedas cênicas realizadas por um palhaço, após receber um tapa, um chute ou bofetão, ou quando esbarra ou escorrega em algo" (SESC, 2014, p. 126).

8 Báscula é um "aparelho semelhante a uma gangorra usado para dar impulso na execução de números de saltos. Um dos acrobatas se posiciona em um dos lados do aparelho enquanto seu parceiro salta sobre o outro, dando assim o impulso para que ele realize movimentos como saltos mortais e piruetas" (SESC, 2014, p. 126).
} 
grandes mestres circenses, como Michel Dallaire ${ }^{9}$, Daniel Pean (Pepe), Joel Suty, Tortell Poltrona ${ }^{10}$, entre outros. Nesses mais de 20 anos trabalhando com o Circo, dividi meu tempo dando aulas, workshops, fazendo direção técnica de espetáculos e, também, desenvolvendo e fabricando aparelhos de circo. Hoje ${ }^{11}$, trabalho com um número acrobático-cascata de barra fixa ${ }^{12}$, com o qual participei de festivais de circo, cabarés e teatros de variedade em muitos países. Também, tive participação em companhias como Los Galindos $^{13}$, Circ Cric, Cirque Gosh, Los Gingers, Familia Bolondo, La Minima, Chocobrothers. Minha atuação com a companhia Los Galindos merece destaque ${ }^{14}$, por ter sido a primeira na qual trabalhei, por eles investirem em mim. Foi com eles que aprendi a respeitar e amar esse ofício.

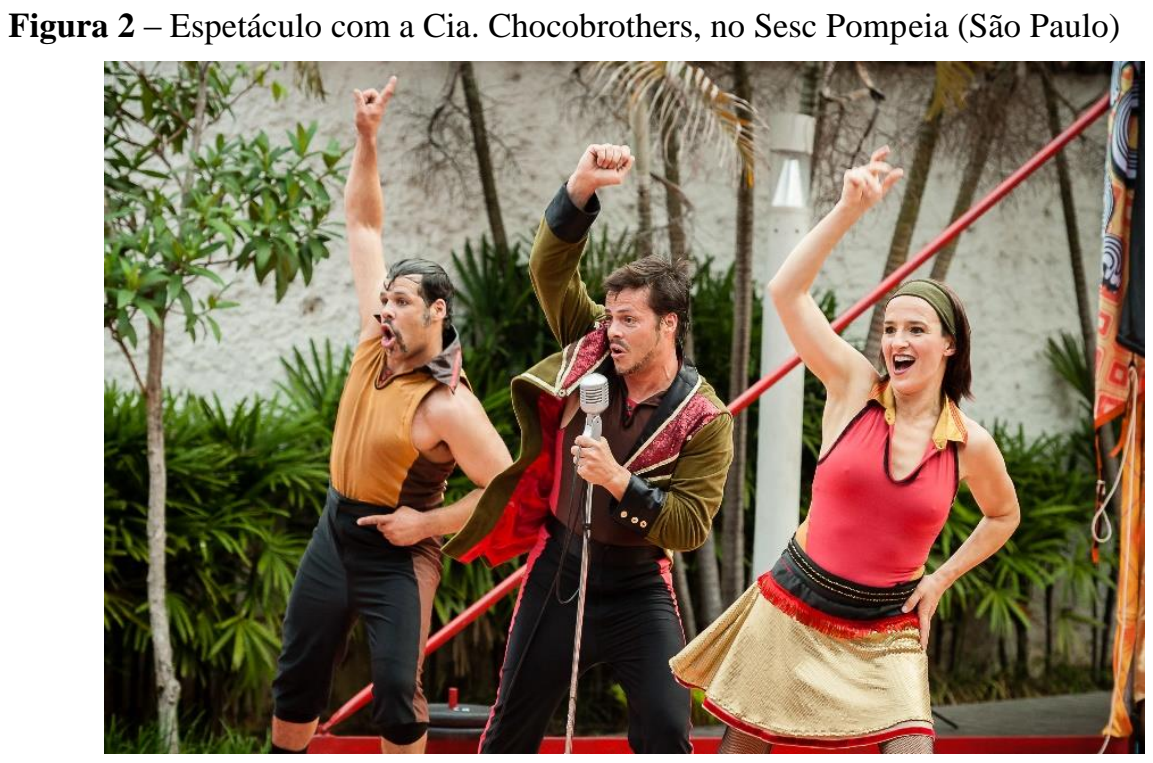

Fonte: Paulo Barbuto.

Minha formação em Educação Física e minha experiência esportiva tiveram e continuam tendo uma contribuição imensa em minha carreira como circense e como pessoa. Eu sempre gostei muito de estudar o efeito do treino e o uso do corpo e sua longevidade. Agora, chegando aos meus 50 anos, posso começar a falar, com alguma propriedade, do objetivo de continuar ativo por muito mais anos.

O Circo é uma área das Artes com exigência física e psicológica muito grande. Em um contrato de

\footnotetext{
9 Palhaço canadense que fez parte do elenco do Cirque du Soleil, referência no circo contemporâneo (Hert, 2014).

10 Palhaço espanhol fundador do grupo Palhaços Sem Fronteiras (Jordá, 1995).

${ }^{11}$ Entrevista realizada em Setembro de 2019.

12 Barra fixa é um "aparelho de ginástica que consiste em uma barra roliça horizontal fixada em dois apoios verticais, na qual o acrobata realiza sequências de giros e saltos” (SESC, 2013, p. 150).

${ }^{13}$ Ver mais em: https://losgalindos.net.

${ }^{14}$ Essa e outras importantes companhias são mais detalhadamente descritas em Jané e Minguet (2006).
} 
circo, pode-se chegar a fazer 13,17, ou mais atuações por semana, durante meses, com um alto nível performático e de alto risco. Um artista deve estar preparado para controlar o estresse. Cada corpo é distinto e reage de maneira diferente. É preciso aprender a escutar. Acredito em um equilíbrio entre as áreas do conhecimento: por um lado, a ciência do treinamento e, por outro, o empirismo do Circo. Acho que cada área deve olhar para a outra com respeito, escuta e flexibilidade.

Vivo aplicando e aprimorando diariamente meus conhecimentos sobre Nutrição, Preparação Física, Preparação Psicológica, Controle do estresse, Treinamento, etc. Para mim, esse equilíbrio é grande indicador de saúde e permite longevidade artística e pessoal. Acho que a grande contribuição foi aprender, na faculdade, cada corpo diferente do outro. Temos que entender e respeitar essa infinita diversidade dos corpos. Curiosamente, nos espetáculos de circo, essa diversidade é muito valorizada.

Meu maior desafio foi trocar de ofício, de professor à artista. Eu não tinha nem ideia de como fazer e do que fazer com minhas habilidades. Um dia, na criação do espetáculo Amálgama, da Cia. Los Galindos, estávamos improvisando e Michel Dalaire ${ }^{15}$ estava como diretor da cia. Foi o primeiro show em que trabalhei profissionalmente. Eu já não sabia mais o que fazer, e comecei a fazer acrobacia e a cair. Ele olhou para mim e disse: amanhã, quero ver uma cena de cascatas com os palhaços. A partir desse dia, soube que precisamente o que eu queria fazer no Circo era cascata e tudo ficou mais claro e fácil. Foi uma honra poder estar com Los Galindos e com Michel, uma oportunidade de ouro poder trabalhar com os dois durante uns quatro anos. Depois, sempre estivemos em contato nas novas criações, e eu sempre buscava ajuda e aconselhamento. Ele foi meu grande maestro!

Entendo que minha grande conquista foi aprender esse ofício. Já faz mais de 20 anos que vivo de circo, viajando, atuando e desfrutando dessa vida. Trabalho com o que eu gosto, junto da minha família, e ter tido a sorte de conhecer gente tão interessante, poder trocar experiências e aprender a respeitar as diversidades. Tive a oportunidade de performar com grandes nomes do circo mundial, os quais me ensinaram muito mais com sua forma de ser do que com o que faziam no picadeiro. O Circo permite ter uma liberdade que poucas profissões oferecem, possibilita-nos viajar e conhecer culturas diferentes. Mas não é fácil!

\footnotetext{
${ }^{15}$ Palhaço, diretor e formador de palhaços, nascido em Québec (Canadá) e residente na França há mais de 25 anos. Trabalhou em empresas como Bebelle, Ratatouille e Cirque du Soleil, em Québec, e com sua empresa Cíe. Contre Pour, entre outros.
} 


\subsection{Como você vê a relação entre o Circo e a Educação Física?}

Eu conheço diversos artistas que tiveram formação no esporte ou que cursaram Educação Física. O Jöel Suty participou de três olimpíadas, duas como ginasta e uma como atleta de saltos ornamentais. Depois, como portor $^{16}$ de quadrante fixo ${ }^{17}$, consagrou-se internacionalmente. Eu conheço diversos artistas de terceira, quarta geração de circo, os quais diziam que seus antepassados tinham sido ginastas e que, depois, ingressaram no Circo, criaram raízes e inspiraram as gerações seguintes. Realmente, não é um fato tão recente como se pensa. ${ }^{18}$

Essa aproximação dos profissionais do treinamento tem-se desenvolvido uma melhora na aprendizagem e na execução técnica em alguns aparelhos. André Simard foi um ginasta canadense que revolucionou o mundo do circo nos anos 1990, dedicou-se ao trapézio em balanço e às coreografias aéreas, deu uma nova dinâmica aos exercícios e desenvolveu uma "autolonja" - sistema de cinturão com elástico que permite dar mais autonomia e segurança ao trapezista. No quadrante aéreo e duplo trapézio, hoje, usase uma adaptação da técnica das argolas da ginástica, um método desenvolvido por um professor de ginástica russo, chamado Yuri Sakalov, que trabalha na Escola Superior de Circo de Bruxelas (ESAC), na Bélgica.

Em 2003, quando conheci o professor Marco Bortoleto, começamos a treinar no Instituto Nacional de Educação Física de Catalunha (INEFC) ${ }^{19}$, em Barcelona, Espanha, onde conhecemos e influenciamos alguns atletas a entrar no mundo do circo. Era um espaço incrível, que pouca gente usava; muito menos para treinar circo. Ao observar uma aproximação dos "cirqueros", o Prof. Dr. Michel Marina, do INEFCBarcelona, e a Profa. Dra Mercè Mateu, à época docente do INEFC-Lleida, contribuíram para abrir o magnífico ginásio de ginástica - usado nos Jogos Olímpicos de Barcelona, em 1992, para artistas de circo e de hip-hop que queriam treinar acrobacia. Foi um intercâmbio excelente! Éramos quatro ou cinco que tínhamos conhecimento do Circo. Aprendemos muito sobre preparação corporal, pois havia bons professores dispostos a trocar experiências. Foi uma época bem interessante, em que fiz amigos para toda a vida. Desse intercâmbio, saíram grandes artistas com formação em Educação Física ${ }^{20}$, muitos deles ainda circulando nos grandes festivais e companhias do mundo.

\footnotetext{
16 Pessoa que fica "sustentando o aparelho e a demonstração do outro artista (o volante) ou tendo a mesma função nos números aéreos" (SESC, 2013, p. 155).

17 “Aparelho tradicional para a execução de acrobacias aéreas" (SESC, 2013, p. 155).

${ }^{18}$ A relação entre circo e ginástica sofre aproximações e distanciamentos ao longo da história, e isso se deve à diversidade de fatores socioculturais, político-econômicos, entre outros (Bortoleto, 2010).

${ }^{19}$ Ver: https://inefc.gencat.cat/ca/inici

${ }^{20}$ Como Gemma Palomar, Julián González e Leticia Garcia, entre outros.
} 


\subsection{Caro Gustavo, quais conselhos sobre cuidados com a saúde e o treinamento você poderia deixar para os leitores?}

Tem uma sábia frase que um dia me disse o Prof. Dr. João Batista Freire ${ }^{21}$ : "Você não precisa saber de tudo, tem que ter um amigo que saiba". Eu sempre procurei amigos que pudessem me orientar, tirar minhas dúvidas. Quando estava no Brasil, aconselhava-me e treinava com Alexandre Moreira - agora, professor doutor da Universidade de São Paulo (USP) -, que sempre seguiu a linha do treinamento russo.

Quando tive minha primeira operação, quem me passou os treinos foi outro grande amigo de classe na FEF-Unicamp, Fabio Roberto Miranda, que também treinava com a linha russa. Conseguimos uma recuperação em três meses de muito trabalho. Escutando o corpo e com bons profissionais, foi possível não perder uma temporada inteira. Hoje, tenho um médico osteopata francês que também combina conhecimentos de nutrição natural, com quem faço revisões periódicas, principalmente antes de assinar contratos para realizar muitas atuações ou uma temporada completa.

Um artista circense deve sempre pensar a longo prazo, como um atleta. É um ofício de pode durar muitos anos, e, para isso acontecer, o profissional que trabalha com o corpo precisa aprender a escutá-lo, saber a hora de parar, entender os sinais de fadiga física, além dos sinais de fadiga emocional. O estresse pode ter consequências muito graves (acidentes ou lesões). Precisamos entender a necessidade de equilíbrio do corpo entre atividade física, alimentação, meditação e controle do estresse. Com essa atenção, entendo que cada pessoa elabora seu próprio método para manter uma boa saúde e, com isso, garante as condições para sustentar sua carreira por muitos anos.

\subsection{Com base no que nos contou até agora, você acredita que criatividade e segurança são elementos fundamentais?}

Sim, totalmente. Nesse sentido, sempre gostei muito de outro tema, o desenho e a construção de aparelhos de circo. Eu sempre tive uma preocupação com a praticidade, a performance e o transporte.

Em 2002, fizemos uma expedição à África, com o grupo Palhaços sem Fronteiras. Na ocasião,

\footnotetext{
${ }^{21}$ Professor aposentado pela Universidade Estadual de Campinas. Graduado em Educação Física pela Faculdade de Educação Física de Santo André (1973), mestre pela Universidade de São Paulo (1982) e doutor em Psicologia Educacional pela Universidade de São Paulo (1991).
} 
queríamos levar uma báscula, mas era difícil, pelo transporte e pela logística. Acabamos levando uma madeira e um rolo de plástico, para fazer de base, e pedimos um colchão de dormir. Conseguimos fazer coisas divertidas com esse material! A partir daí, desenvolvi uma báscula pequena, que tinha uma medida boa para viajar em avião e me dava condições de fazer bons truques. Essa báscula foi vendida para várias companhias de circo de rua. Agora, estou desenvolvendo uma báscula grande, que se pode desmontar em duas partes, para facilitar o transporte.

Sempre busco conselhos com amigos e profissionais de circo, que também são construtores ou viraram engenheiros, tanto por uma questão de segurança, desenho, ou para a escolha de diferentes tipos de materiais. É muito importante que o profissional tenha em conta as peculiaridades do Circo, saber sobre as condições de atuação, montagem e transporte. Eu já vi projetos belíssimos que, por tempo de montagem, alta exigência de ficha técnica ou por dificuldade no transporte, não tiveram uma longa vida artística. Criar, inclusive, os aparelhos, parece-me muito importante.

Eu acho as questões de segurança muito importantes, também. Todo artista de circo precisa entender e conhecer o aparelho que utiliza, suas peculiaridades de construção, material, desenho e resistência, e os riscos que corre em cada montagem e atuação, bem como a técnica desenvolvida para realizar sua performance. $\mathrm{O}$ artista de circo precisa procurar informações com outros profissionais, mas nunca passar toda a responsabilidade total a esse terceiro. Saber que, se alguém vai cair e se dar mal, a responsabilidade vai ser de quem está executando o aparelho. Assim, não adianta culpar outra pessoa. O máximo responsável é sempre o artista, é ele quem vai ficar sem trabalho, machucar-se. Não é o montador, nem o engenheiro!

Esta é uma reflexão que posso deixar: se o artista não vê claras as condições para atuar - seja por condições de clima, por problemas de montagem ou por não se sentir fisicamente preparado -, então, que não atue ou diminua o risco, por exemplo, tirando sequências técnicas de maior perigo. Minha experiência diz que esse momento sempre será uma decisão difícil a ser tomada. Mais ainda: as regras de segurança devem estar claras dentro do grupo de artistas e, se possível, no contrato de trabalho, para que ambas as partes saibam como lidar em cada situação previamente acordada.

\subsection{Como tem sido combinar a carreira profissional e a vida familiar? Como é o estilo de vida do Gustavo artista circense?}

Minha companheira Silvia trabalha com Circo desde muito antes que eu. Nosso filho Yuri tem 8 anos e sempre esteve com a gente, seja viajando ou sentado nas coxias ou nos camarins de algum teatro. 
Desde pequeno, ele nos acompanha e gosta muito. A vida itinerante tem coisas boas e não tão boas. Antes, com as companhias de circo de rua, fazíamos temporadas de verão viajando até 45 mil km por ano, visitando umas 70 cidades diferentes. Íamos em vans, ficávamos em hotéis, e toda turnê era gerenciada por nós mesmos. Quando nasceu o Yuri, tivemos que buscar outras formas de trabalho com o Circo. Trabalhamos em cabarés na Alemanha, com condições de trabalho espetaculares, trabalhando num mesmo teatro por toda uma temporada, tendo um ritmo de vida típico da cidade (vida urbana). Em todos os casos, trabalhase muito, quase sempre à noite, e bem tarde. Nós nos acostumamos!

Já nos circos de lona, as coisas são diferentes. Você viaja com sua casa, quase sempre tem mais famílias com crianças, como um pequeno bairro do interior. Mesmo que, muitas vezes, não falem as mesmas línguas, no final, estão brincando. A parte difícil são as condições para a instalação do circo: terrenos não são sempre os melhores, quase sempre têm problemas com água, luz, lama, etc. No entanto, não deixa de ser uma experiência mágica. Eu sou um apaixonado pelo circo itinerante de lona!

Atualmente, temos uma base - um lugar para viver a maior parte do tempo - na Catalunha, perto da cidade de Barcelona. Para Yuri, agora, começa a complicar entre a escola e os amigos, já não é tão divertido viajar tanto. Ano passado, ele esteve todo o ano escolar no Brasil. Infelizmente, não existe um programa de educação à distância no Brasil, e ele não pôde acompanhar a turnê, mas, mesmo assim, foi uma experiência incrível para todos. Nunca foi fácil para uma família de circo itinerante educar os filhos e filhas. Alguns fazem à distância, outros deixam com algum familiar, ou um dos pais deixa o circo por uma temporada para cuidar da educação. Na Europa, alguns circos têm um professor pago pelo estado que faz a temporada com o circo. Estamos procurando uma maneira de agradar a todos em nossa família e ter uma base um pouco mais fixa, sem perder a itinerância. Parece estar funcionando bem.

Figura 3 - Espetáculo da Família Bolondo - Circ de Hiver do Ateneu, Mercat de les Flors (Barcelona)

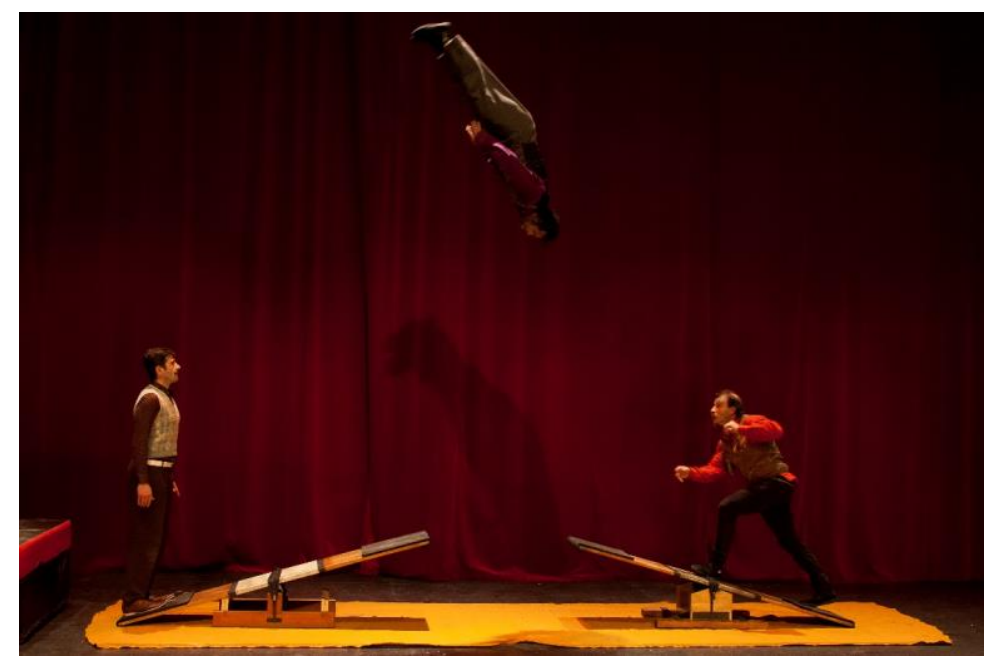

Fonte: Carles Caleró. 


\subsection{Na sua opinião, como está o mercado de trabalho para o artista circense no Brasil e no exterior?}

Agora mesmo, a situação está muito difícil para toda a população, mas, nas áreas que trabalham com cultura, a coisa está realmente feia. No Brasil, não existe uma valorização da cultura e, nessa hora de crise, uma das primeiras coisas que se dispensa é o que se crê supérfluo. Está todo mundo tentando fazer milagre e se reinventar, essa é uma característica do Circo. Ele tem uma capacidade de adaptação enorme, mas não será fácil a volta.

Aqui na Europa, todo o circuito internacional está parado. Dependendo do país, existe uma ajuda melhor ou pior: Bélgica e França pagaram 100\% de todos os contratos assinados e anulados devido ao COVID-19. Na Espanha, houve uma ajuda, mas ficou em $30 \%$ ou $40 \%$ mais ou menos que o valor anterior, e com uma burocracia enorme. Existem países que valorizam o artista e reconhecem a sua importância social, outros nem tanto. Mas, como em todo o mundo, é um improviso total, ninguém sabe nada. Cada um vai fazendo o que pode. Aqui, algumas cidades lutaram bastante para continuar com a programação dos seus festivais, com o slogan "Cultura Segura". Programa-se com um protocolo de segurança, público com máscara, lotação limitada, respeitando a distância de segurança. Mesmo para os espetáculos grátis, tem que ter reserva, nome e endereço para contato, no caso de que seja necessário o rastreamento. A programação é feita com artistas regionais. Pelo menos, na Catalunha, não foi registrado nenhum contágio significativo nas programações culturais, tanto na rua como nos teatros. Mas, certamente, fomos impactados e esperamos dias melhores!

\section{Considerações: Educação Física e Circo ou vice-versa - mútua contribuição}

Como é possível observar no depoimento expresso por nosso entrevistado, a Educação Física e o Circo podem se ajudar mutuamente. Todo o conhecimento de treinamento e educação motriz são de grande ajuda para a conquista e a manutenção de um truque ou número de circo. A transmissão do conhecimento, que agora não se dá mais necessariamente na família, pode ocorrer em outro espaço: o das escolas de circo, onde o profissional de educação física tem muito a contribuir. O Circo tem a capacidade de acolher a todos. Um artista deve valorizar as suas peculiaridades. Quanto mais identidade sua performance ter, mais único será seu trabalho e mais difícil será sua substituição. O Circo valoriza mais a variedade do que a unidade dos corpos, e procura destacar as diferenças e peculiaridades. No treinamento, sempre vamos na direção da 
performance, melhora da execução técnica, biomecânica, refinamento do gesto na direção do melhor resultado, o que cria, na maioria das vezes, um corpo padronizado para cada esporte.

No âmbito escolar, o Circo é uma ferramenta muito valiosa e não tão complexa de ser utilizada. Pode ser uma alternativa aos esportes ou jogos, não somente voltada para o desenvolvimento físico, mas também para o desenvolvimento cognitivo e a criatividade. O Circo é uma opção interessante para o profissional de educação física também na área social. O Circo evoluiu, transformando-se em ferramenta de intervenção social, educativa e de gestão comunitária, hoje conhecido como Circo Social. A contribuição é mútua, mas se deve estar atento para respeitar, entender e aproveitar suas particularidades.

A Arte do Circo parece ter seduzido muitos professores de educação física ${ }^{22}$, permitindo, inclusive, que alguns se tornassem artistas profissionais ${ }^{23}$, outros pesquisadores, e, muitos mais, entusiastas que levaram o Circo para suas aulas (ONTAÑ́N, DUPRAT, BORTOLETO, 2012). Há, também, quem tenha feito o caminho inverso, iniciando carreira no circo, tornando-se profissional ou pesquisador na Educação Física $^{24}$. Em todos os casos, parece que o corpo, mediador desse diálogo (BOLOGNESI, 2006), ganhou bons aliados, mostrando a importância da interação entre Circo e Educação Física. No entanto, a formação superior em Educação Física parece não estar muito atenta a tudo isso, como mostram estudos recentes (MIRANDA, AYOUB, 2017 e 2018; TUCUNDUVA, BORTOLETO, 2019). Ou seja, precisamos seguir trabalhando nessa longa e promissora causa, como nos encorajou o pedagogo francês Alain Fouchet (2006) no início da década de 1990.

Parece-nos que o caso de Gustavo Arruda de Carvalho revela a busca constante, o estudo e a dedicação componentes fundamentais para o sucesso profissional em uma longa e vitoriosa carreira profissional. E, como vimos, ele não é uma exceção, certamente!

Guga e sua esposa, a também artista circense Silvia Compte, seguem itinerando por diversos festivais pelo mundo, realizando temporadas em circos europeus ${ }^{25}$. Em suma, deixa-nos uma clara mensagem, tanto para entusiastas quanto para todos os profissionais de circo, especialmente, no que concerne à construção da carreira profissional. Como ele fez questão de ressaltar: "realmente, façam o que gostam e sejam competentes no que fazem, que um dia o reconhecimento chegará. Que trabalhem para viver e não vivam para trabalhar. Filosofia de bar!”

\footnotetext{
${ }^{22}$ Dentre eles, Rodrigo Mallet Duprat, Teresa Ontañón Barragán, Josep Invernó Curros, Aline Caramés, Leonora Cardani, Camila Ribeiro, Diego L. Ferreira, Marcos Tiaen, entre outros.

${ }^{23}$ Para citar alguns que acompanhamos, Mariana Maekawa, André Sabatino, Martin Sabatino, Daniela Helena Calça, Tiago Sales Claro, Marcio Parma, João Gabriel Nunes.

${ }^{24}$ Marcelo Marques, Júlio Rodrigues, Fábio Nunes da Silva.

${ }^{25}$ Ver: https://www.facebook.com/GugaSilvia/
} 


\section{Referências}

BOLOGNESI, Mario F. Circo e teatro: aproximações e conflitos. Sala Preta, v. 6, p. 9-19, 2006. Disponível em: https://www.revistas.usp.br/salapreta/article/view/57288 Acesso em: 15012021.

BORTOLETO, Marco A. C. A ginástica e as atividades circenses. In: GAIO, R. (Orgs.). A ginástica em questão: corpo e movimento. v. 2. São Paulo: Phorte Editora, 2010.

. Entre o esporte e a arte circense: entrevista com Mariana Maekawa. Conexões - Revista da Faculdade de Educação Física da UNICAMP, v. 13, número especial, p. 230-235, maio, 2015. Disponível em: https://periodicos.sbu.unicamp.br/ojs/index.php/conexoes/article/view/8637586 Acesso em: 20012021.

Palhaços sem fronteiras: O circo a serviço da sociedade. PerCursos, v. 6, n. 2, 2007. Disponível em: https://www.revistas.udesc.br/index.php/percursos/article/view/1454 Acesso em: 20012021.

BORTOLETO, Marco A. C.; CARVALHO, Gustavo A. Reflexões sobre o Circo e a Educação Física. Revista Corpoconsciência, Santo André, n. 11, janeiro, 2003. Disponível em: https://periodicoscientificos.ufmt.br/ojs/index.php/corpoconsciencia/article/view/3923 Acesso em: 2001 2021.

BORTOLETO, Marco A. C.; DUPRAT, Rodrigo M.; TUCUNDUVA, Bruno P. Atividades circenses na FEF-UNICAMP: a construção de uma nova área de estudos e pesquisa. In: BORTOLETO, M. A. C.; ONTAÑ́́N, T. B. ; SILVA, E . Circo: horizontes educativos. 1. ed. Campinas - SP: Autores Associados, 2016. v. 1.

BORTOLETO, Marco A. C.; MIRANDA, Rita C.F. Não foi casualidade - o circo como opção profissional: entrevista com André Sabatino. Conexões: Educ. Fís., Esporte e Saúde, Campinas, v. 16, n. 3, p. 395408, jul./set. $2018 . \quad$ Disponível em: https://periodicos.sbu.unicamp.br/ojs/index.php/conexoes/article/download/8652918/18610/43533 Acesso em: 22012021.

EVRARD, Beatriz. Espaço em movimento: cenografia e circo. Ano 2017. f. Dissertação (Mestrado em Artes da Cena), Universidade de São Paulo, São Paulo, Ano. Disponível em: https://www.teses.usp.br/teses/disponiveis/27/27156/tde-30052017-114818/pt-br.php Acesso em: 2201 2021

FOUCHET, Alain. Las artes del circo: una aventura pedagógica. Buenos Aires: Editorial Stadium, 2006. GÓIS JÚNIOR, Edivaldo; HAUFFE, Míriam K. A Educação Física e o funâmbulo: entre a arte circense e a ciência (século XIX e início do século XX). Rev. Bras. Ciênc. Esporte, v. 36, n. 2, p. 547-559, 2014. Disponível em: https://www.scielo.br/scielo.php?pid=S010132892014000200547\&script=sci_abstract\&tlng=pt Acesso em: 22012021.

HERT, Philippe. Apprendre à faire le clown. Techniques \& Culture. Revue semestrielle d'anthropologie des techniques, n. 62, p. 30-47, 2014. Disponível em: https://journals.openedition.org/tc/8285?lang=en Acesso em: 22012021.

JANÉ, Jordi; MINGUET, Joan M. (Orgs.). Catàleg de l'exposició “Circ contemporani català, l'art del risc”. Barcelona: Krtu / Departament de Cultura de la Generalitat / Triangle postals, 2006.

JORDÀ, Vicenç P. Clowns Without Frontiers. Catalònia, n. 41, p. 46-47, 1995.

LOPES, Daniel de C.; EHRENBERG, Mônica C. Entre o pódio e o picadeiro: o sportsman circense Zeca Floriano. Revista História da Educação, v. 24, 2020. Disponível em: https://seer.ufrgs.br/asphe/article/view/94488 Acesso em: 22012021. 
MIRANDA, Rita de C. F.; AYOUB, Eliana. Por entre as brechas dos muros da universidade: o circo como componente curricular na formação inicial em educação física. Revista Portuguesa de Educação, v. 30. N .2, 2017. Disponível em: https://revistas.rcaap.pt/rpe/article/view/11867 Acesso em: 10122020.

MELO, Victor A. de; PERES, Fabio de F. A gymnastica no tempo do Império. Rio de Janeiro: 7Letras/Faperj, 2014.

MIRANDA, Rita de C. F.; AYOUB, Eliana. As práticas circenses no "tear" da formação inicial em Educação Física: novas tessituras para além da lona. Movimento, v. 22, n. 1, p. 187-198, 2016. Disponível em: https://seer.ufrgs.br/Movimento/article/view/55179 Acesso em: 10092020.

ONTAÑón, Teresa B.; BORTOLETO, Marco A. C. Entrevista realizada com o Professor Dr. León Guzmán (Kiko). Conexões: Educação Física, Esporte e Saúde, v. 10, n. 2, p. 235-240, 2012. Disponível em: https://periodicos.sbu.unicamp.br/ojs/index.php/conexoes/article/view/8637684 Acesso em: 2101 2021.

ONTAÑÓN, Teresa B.; DUPRAT, Rodrigo M.; BORTOLETO, Marco A. C. Educação Física e atividades circenses: "o estado da arte". Movimento, Porto Alegre, p. 149-168, abr. 2012. Disponível https://seer.ufrgs.br/Movimento/article/view/22960 Acesso em: 20012021.

RIBEIRO, Camila da S. Artistas/Atletas: aproximações e intersecções entre o esporte e o novo circo. 2015. 132 f. Dissertação (Mestrado em Educação Física), Universidade Federal de Pelotas, Pelotas, 2015. Disponível em: http://wp.ufpel.edu.br/ppgef/arquivo-de-dissertacoes-2015 Acesso em: 20012021

RIBEIRO, Camila da S.; RIGO, L. C.; BORTOLETO, Marco A. C. Circo e Esporte: transição de carreira e capital corporal. Repertório: Teatro \& Dança (online), v. 23, p. 46-52, 2020. Disponível em: https://periodicos.ufba.br/index.php/revteatro/article/view/35559/0 Acesso em: 20012021

SOARES, Carmen L. Acrobacias e Acrobatas: notas para um estudo do corpo". Em: Bruhns, Heloisa Turini; Gutierrez, Gustavo Luis (org.) Representações do Lúdico. Campinas: 2001, v. 1. p. 33-42.

SESC. Circos: Festival Internacional Sesc de Circo. São Paulo: Sesc São Paulo, 2013.

Circos: Festival Internacional Sesc de Circo. São Paulo: Sesc São Paulo, 2014.

TUCUNDUVA, Bruno B. P.; BORTOLETO, Marco A. C. O circo e a inovação curricular na formação de professores de Educação Física no Brasil. Movimento, Porto Alegre, v. 25, e25055, out. 2019. Disponível em: https://seer.ufrgs.br/Movimento/article/view/88131 Acesso em: 28122020.

\section{Como citar este artigo}

BORTOLETO, M. A. C.; BARRETO, M. L. A. O Circo como profissão: a formação em Educação Física como suporte para a carreira artística de Gustavo Arruda de Carvalho. Revista Kinesis, Santa Maria, v. 39, p.01-15, 2021.

* O presente trabalho foi realizado com apoio da Coordenação de Aperfeiçoamento de Pessoal de Nível Superior - Brasil (CAPES) - Código de Financiamento 001 - This study was financed in part by the Coordenação de Aperfeiçoamento de Pessoal de Nível Superior - Brasil (CAPES) - Finance Code 001 